\title{
Coronavirus Disease 2019 (COVID-19): Morocco Interrupting the Transmission by Ethics, Logistics, and Therapeutics Efforts
}

\author{
Soraia El Baz ${ }^{1^{*}}$, Boujamâa Imziln ${ }^{1}$
}

\author{
${ }^{1}$ Laboratory of Microbial \\ Biotechnologies, Agrosciences and \\ Environment (BioMAgE), Cadi \\ Ayyad University, Faculty of \\ Sciences Semlalia, P.O. Box 2390, \\ Marrakech 40000, Morocco
}

\begin{abstract}
Since the first case of 2019 novel coronavirus (COVID-19) identified on 02 March 2020 in Morocco, the number of cases rapidly increased, resulting in 3046 cases including 143 deaths as of 20 April 2020. Morocco used every possibility (socio-economic and medical) to control and to limit the spread of COVID-19 and support the implementation of social distancing measures to quickly control the outbreak. The percentage of death was $4.7 \%$ as of 20 April 2020, and increases with older age. The median age of the deaths was 65 years. Moroccan government noted that $80 \%$ of the death had health problems, $15 \%$ of positive COVID-19 cases show no symptoms and only $11.5 \%$ of patients were recovered. This report examines the impact of the ongoing pandemic of COVID-19 in Morocco. The Moroccan government has considered being more effective in responding to the pandemic. Persistent efforts have been made to limit the transmission of COVID-19, and many strategies to protect people against COVID-19 is running well to keep the spread of coronavirus under control in comparison with other countries in Europe or Africa (especially North Africa). In this report, in contrast, the situation demonstrates the need of rapid and accurate detection and identification methods that can be used in hospitals bearing the burden of identifying and treating patients. Also, this paper demonstrate that the different measures adapted by Morocco can be a good example for other developing countries and used to fight COVID-19 before it reaches the poorest countries of the world.
\end{abstract}

Keywords: coronavirus, COVID-19, Morocco, containment, chloroquine, social distancing

Early reports (by Dr. Jianguo $\mathrm{Xu}$, an academician of the Chinese Academy of Engineering) announced that a new-type coronavirus, named by World Health Organization (WHO) on 11 February 2020 as the 2019-new coronavirus (COVID-19), had caused this outbreak [1]. The biology and transmission of this virus until know is limited [2,3]. The symptoms of COVID-19 infection appear after 5 days of incubation period [4]. It is mainly spreading through (a) verbal contamination, (b) contamination through eatables, and (c) contamination due to contact with the infected person [5]. The most common symptoms at onset of COVID-19 illness are fever, cough, and fatigue [6,7]. Besides, coronavirus disease 2019 (COVID-19) results in respiratory syndrome and can cause remarkable cardiovascular impacts in form of myocardial injury, myocarditis, heart failure and arrhythmia. Elderly patients and those with comorbidities are most susceptible for this infection, and will have the worst prognosis [8]. Our report aimed to examine all ethics, logistics and therapeutics efforts adapted by Moroccan government to protect people against the transmission of COVID19.

At the moment of a massive increase of cases reported all over the world especially in USA, Italy, France, and Spain. Globally, the number of confirmed cases as of this writing (20 April 2020) has reached 2 Million confirmed COVID-19 cases in more than 200 countries and territories, and deaths over 157 847. The World Health Organization (WHO) reported 84237 cases
Received: 23.04.2020,

https://doi.org/10.5799/jcei/8214 


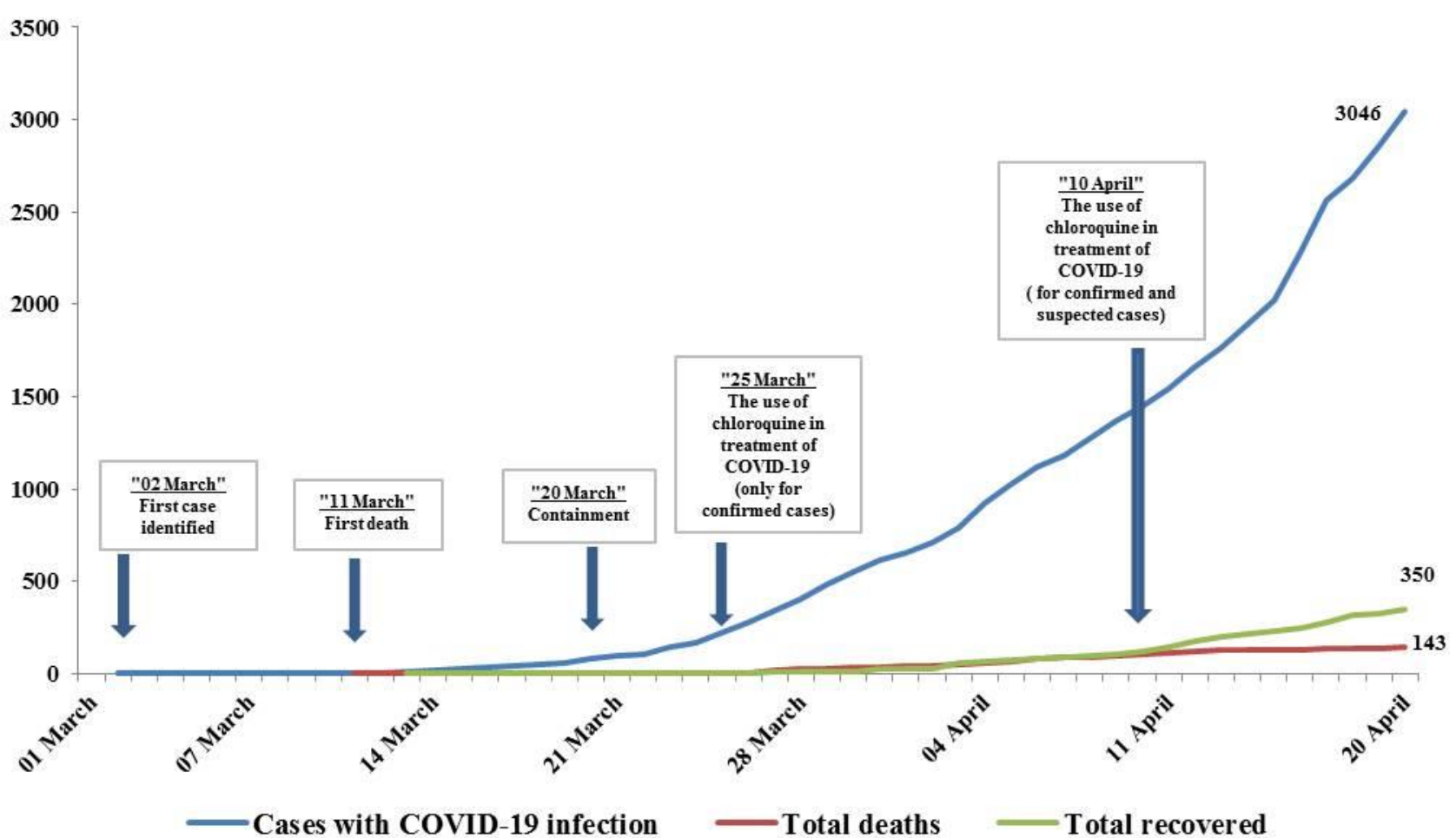

Figure 1. The chronological incidence of COVID-19 infections, death cases and recovered cases in Morocco. First Infections with COVID19 appears in 02 March 2020. At the time of preparing this manuscript, 20 April 2020 there have been 3046 people who have contracted the infection in Morocco including 143 deaths

and 4642 death cases in China; 178972 cases and 23660 death cases in Italy; 195944 cases and 20453 death cases in Spain; and 111463 cases and 19689 death cases in France [9]. The first case of COVID-19 infection confirmed in Morocco was reported in Casablanca city on 02 March 2020 (Passenger arriving from coronavirus-ridden Italy) (https://www.covidmaroc.ma; https://www.sante.gov.ma). Two days after, the second case was detected. After that, from 10 to 18 March a new case was discovered each day. Thereafter, more than 10 cases were detected each day from 18 to 22 March. Between 23 and 24 March more than 20 cases were detected each day. Then, more than 50 cases were detected each day in the period from 25 to 31 March. However, the number of new confirmed cases of COVID-19 infection started to increase rapidly since 12 April with more than 100 new cases confirmed (Figure 1).

Health ministry has so far screened more than 22000 for the novel coronavirus. Following such screening, 3046 individuals (51\% men, $49 \%$ women) were tested positive for coronavirus infection in Morocco, 13340 were negative (https://www.covidmaroc.ma). $96 \%$ of the cases did not have a complicated situation and just $4 \%$ needs emergency. The median age of the infected case was 42 years (varying from 2 months $\sim 96$ years old).

All of the 8 patients confirmed before March 13, were imported cases from France (5), Italy (2) and one patient from Spain. After 14 days, the first local case positive was registered with other 8 imported patients were confirmed (4
Spain, 3 Italy and 1 France). On 28 March, 59\% of the cases were local and $41 \%$ were imported. On 03 April, 75\% of the cases were local and 25\% were imported. But, since 09 April, the Moroccan government announced that more than $90 \%$ of the cases were local and less than $10 \%$ were imported.

The Moroccan National Health Commission reported that only $3 \%$ of patients were recovered among the reported 556 cases of COVID-19 as of 30 March. Fatality rate was approximately $6 \%$ (33 persons), 33\% of the death were imported and $66 \%$ were local. Moreover, on 20 April the commission noted that $80 \%$ of the death had chronic medical conditions (such as diabetes, lung disease and heart disease), and $15 \%$ of positive COVID-19 cases show no symptoms. Unfortunately, the total deaths increased to $143(4.7 \%)$ and the median age of the deaths was 65 years (66\% men, 34\% women). However, total recovered increased to 350 (11.5\%) and the median age of the deaths was 48 years $(50 \%$ men, $50 \%$ women).

Since the coronavirus is transmitted by respiratory droplets, it thus requires close proximity of people for transmission. Social distancing creates the needed barrier to break the chain of admission. Also, quarantine is one of the oldest methods of containing communicable diseases. However, isolation and institutional quarantining of people who have been in contact with a confirmed or likely case is unrealistic during pandemics [10]. 
On 16 March 2020, to surely alleviated concerns of people and to respond to the mounting number of cases of COVID19, the Moroccan authorities has quickly stepped up the disinfection of trains and airplanes and checks of passengers due to this pandemic. On 20 March 2020, the Morocco authorities has raised the COVID-19 alert level to the highest and decided to apply a total containment until 20 May 2020 in all Moroccan cities, to limit the transmission of the virus in society. The government has applied this strategy to avoid the situation in Italy and in Spain, who recorded a high number of COVID-19 positive patients and deaths. As is known, most Moroccan emigrants live in Italy, Spain and France, and after the emergence of COVID-19 in these countries, the Moroccan government decided to suspend travel to these countries most affected by the pandemic. Soon after, he decided to close the borders. In order to reduce person-to-person transmission of COVID-19, several extensive measures were applied in Morocco to control the current outbreak: (1) protect or reduce transmission in susceptible populations (children, health care providers, and elderly people) by staying at home and implementation of comprehensive social distancing measures; (2) the public services and facilities provide decontaminating reagents for cleaning hands on a routine basis; (3) cancelling social events, delaying school activities, and all not strictly necessary business activities with the exception of grocery stores, pharmacies and para-pharmacies, and other basic necessities stores and offices; (4) schools and universities have moved classes totally online, teachers deliver their lectures or teaching through an online learning platform and by video conference platforms; (5) the obligatory of wearing masks to prevent the infection especially within families, maintaining distance of at least one meter from any person, performing hand hygiene frequently by using soap and hot water if possible, or an alcohol-based hand rub in public places; (6) detailed information on COVID-19 cases is shared publicly to prevent speculation; (7) psychological counseling centers are activated to help people disturbed by this virus to overcome their fear especially during this period of containment. So it is very clear that Morocco very early put in place a powerful response: it immediately mobilized its industrial fabric by redirecting the factories towards the production of protective masks, hydro-alcoholic gel or even medical equipment including coveralls, gowns, charlottes, over-shoes. Morocco has also worked towards producing $100 \%$ Moroccan artificial respirators. The kingdom established strict containment, deployed the armed forces in support. It has installed several field hospitals and doubled its capacity for resuscitation beds.

Furthermore, many people on the world such as in Vietnam [11] or in USA [10], went to supermarkets, traditional markets, and grocery stores to buy hoarding food, they bought so much that food stalls and some essential goods in selling places have been quickly emptied and become scarce. In Morocco, the government has constantly communicated that there would always be a source of food and essential commodities for 6 months.

After many studies confirms the ability of Hydroxychloroquine to reduce the exacerbation of pneumonia, duration of symptoms and delay of viral clearance all in the absence of severe side effects [12], and as Hydroxychloroquine has the same action on viruses as that of chloroquine, so probably hydroxychloroquine can be prescribed for long periods, which would be therefore the first choice in the treatment of COVID-19 [13]. On 25 March, Moroccan health commission and the government announced the use of chloroquine in treatment of COVID19, but we cannot conclude the effectiveness of this treatment up to 12 days of treatment. Moreover, Moroccan government decided on 10 April, to use chloroquine for patients with suspected or confirmed COVID-19. Therefore, people presenting mild symptoms, or those who have had close contact with other sick or suspected people (family members, work colleagues etc.), were isolated in their home to be submitted later to COVID-19 test. It has been also observed that a lot of family members get sick synchronously.

In another hand, The Moroccan state has made available to universities and research organizations very significant funds to develop scientific research on COVID-19.

The Moroccan government has mobilized all necessary resources to fight off COVID-19, but without the cooperation of all the citizens, in respect of the measures of containment and individual protection, this war will be lost. Also, the treatment of COVID-19 by chloroquine gives humanity hope to be cured of this virus. We applauded the excellent job that has been done so far and demonstrate that the different measures adapted by Morocco can be a good example for other developing countries (especially in Africa), and used to fight COVID-19 before it reaches the poorest countries of the world.

\section{ACKNOWLEDGEMENTS}

The authors want to acknowledge the Editorial office of the journal and all the anonymous reviewers. We also thank the Moroccan government for all its efforts, and all health care workers whom are on the front lines of the pandemic.

Declaration of interest: The authors report no conflicts of interest.

Financial Disclosure: No financial support was received.

\section{REFERENCES}

1. Lu H, Stratton CW, Tang Y-W. Outbreak of Pneumonia of Unknown Etiology in Wuhan, China: The Mystery and the Miracle. J. Med. Virol. 2020;92(4):401-2. doi: $10.1002 / j m v .25678$. 
2. Chen N, Zhou M, Dong X, Qu J, Gong F, Han Y, Qiu Y, Wang J, Liu Y, Wei Y et al. Epidemiological and Clinical Characteristics of 99 Cases of 2019 Novel Coronavirus Pneumonia in Wuhan, China: A Descriptive Study. The Lancet. 2020;395(10223):507-13. doi: 10.1016/S01406736(20)30211-7.

3. Lau H, Khosrawipour V, Kocbach P, Mikolajczyk A, Ichii $\mathrm{H}$, Schubert J, Bania J, Khosrawipour $\mathrm{T}$. Internationally Lost COVID-19 Cases. J Microbiol Immunol Infect. 2020. doi: 10.1016/j.jmii.2020.03.013.

4. Li Q, Guan X, Wu P, Wang X, Zhou L, Tong Y, Ren R, Leung K, Lau E, Wong JY et al. Early Transmission Dynamics in Wuhan, China, of Novel CoronavirusInfected Pneumonia. N Engl J Med. 2020;382(13):1199207. doi: 10.1056/NEJMoa2001316.

5. Majumder P, Biswas P, Majumder S. Application of New TOPSIS Approach to Identify the Most Significant Risk Factor and Continuous Monitoring of Death of COVID19. Electron J Gen Med. 2020;17(6):em234. doi: 10.29333/ejgm/7904.

6. Wang W, Tang J, Wei F. Updated Understanding of the Outbreak of 2019 Novel Coronavirus (2019-nCoV) in Wuhan, China. J. Med. Virol. 2020;92(4):441-7. doi: 10.1002/jmv.25689.

7. Rothan HA, Byrareddy SN. The Epidemiology and Pathogenesis of Coronavirus Disease (COVID-19) Outbreak. J Autoimm. 2020;109:102433. doi: 10.1016/j.jaut.2020.102433.
8. Dakhil ZA, Farhan HA. Cardiovascular Impacts of COVID-19 Pandemic: From Presentation to Management: Current and Future Perspectives. J Clin Exp Invest. 2020;11(3):em00739. doi: 10.5799/jcei/7941.

9. WHO. World Health Organization. Report of the WHO-China Joint Mission on Coronavirus Disease 2019 (COVID-19) Available at: https://www.who.int/ docs/default-source/coronaviruse/situation-reports/ 20200420-sitrep-91-covid-19.pdf?sfvrsn=fcf0670b_4 (Accessed 20 April 2020).

10. Ameh G, Njoku A, Inungu J, Younis M. Rural America and Coronavirus Epidemic Challenges and solutions. EUROPEAN J ENV PUBLI 2020;4(2):em0040. doi: 10.29333/ejeph/8200.

11. Long NN, Khoi BH. An Empirical Study about the Intention to Hoard Food during Covid-19 Pandemic. EURASIA J MATH SCI T. 2020;16(7):em1857. doi: 10.29333/ejmste/8207.

12. Gao J, Tian Z, Yang X. Breakthrough: Chloroquine Phosphate has Shown Apparent Efficacy in Treatment of COVID-19 Associated Pneumonia in Clinical Studies. BioSci Trends. 2020;14(1):72-3. doi: 10.5582/bst.2020.01047.

13. Colson P, Rolain J-M, Lagier J-C, Brouqui P, Raoult D. Chloroquine and Hydroxychloroquine as Available Weapons to Fight COVID-19. Int J Antimicrob Agents. 2020:105932. doi: 10.1016/j.ijantimicag.2020.105932. 